\title{
The unsaid word
}

\author{
Timothy F. Christian, MD, MPA ${ }^{\mathrm{a}}$ \\ a St Francis Hospital, The Heart Center, Roslyn, NY \\ Received Mar 9, 2017; accepted Mar 9, 2017 \\ doi: 10.1007/s12350-017-0886-z
}

\section{See related article, pp. 1046-1053}

We are masters of the unsaid words, but slaves of those we let slip out.

Winston S. Churchill

The US health system is in the midst of a large (and now unpredictable) transformation. There are, in development, a large number of metrics to assess the quality and cost of cardiac care. Assuming these continue to be employed, they will impact on physician and hospital reimbursement, changing the incentive landscape in US medicine. The core of these metrics are the ACC/AHA guidelines. Each metric must show content validity and that is judged by expert panels such as the National Quality Forum and other entities. Often the metric is initiated by the Centers for Medicare and Medicaid Services. Validity is largely based on the degree the metric incorporates the guideline related to it. Consequently, the guidelines have an important role in the economics and practice of medicine in the United States. Once laid down, the guideline will have impact through metric development. Conversely, avoiding a guideline statement in a gray area retains flexibility in practice.

Comparing the European and US guidelines selected by Stirrup, et al, ${ }^{1}$ there are many similar positions. There are a few differences. And there are lots of omissions. Let us first look at some of the guidelines where there is consensus.

\section{COMMON GROUND}

It has been nearly 40 years since Diamond and Forrester introduced Bayesian principles into the

Reprint requests: Timothy F. Christian, MD, MPA, St Francis Hospital, The Heart Center, 100 Port Washington Blvd, Roslyn, NY; timothy.christian@rutgers.edu

J Nucl Cardiol 2017;24:1054-6.

$1071-3581 / \$ 34.00$

Copyright (C) 2017 American Society of Nuclear Cardiology. algorithm for the diagnosis of coronary artery disease. ${ }^{2}$ George Diamond was a creative force and brilliant writer, teaching both the value and the follies associated with specific statistical approaches to medical problems. ${ }^{3-5}$ How gratifying for him to have seen that work form the cornerstone of so many guidelines in cardiology. The concept of pre-test probability dominates the guidelines on suspected $\mathrm{CAD}$ on both sides of the Atlantic. The realization that incremental value in testing is greatest for intermediate risk patients is now widely held. The converse, that noninvasive test results on low and high risk patients at the ends of the pre-test probability curve provide minimal additional clinical value, has also been embraced. While the concept of conditional probability is ubiquitous in the cardiology guidelines now, ${ }^{6}$ it was not always a routine part of clinical practice. This was a great contribution and we are all the wiser from his work.

The other area of commonality that stands out in this guideline comparison is the wide acceptance of medical therapy as an initial strategy in stable patients. The recognition that plaque rupture is often independent of stenosis severity and that the disease of atherosclerosis is diffuse within the vessel has become accepted into clinical practice on both continents. This is in direct response to the results of the COURAGE trial where outcomes for patients with coronary artery disease (CAD) were not impacted by revascularization in stable patients as well as other studies. ${ }^{7}$ Consequently, a medical approach is now widely endorsed as first line therapy for stable coronary artery disease. This is another landmark achievement.

\section{DIFFERENCES}

There are few differences of significance in these guidelines. There are instances of less enthusiastic recommendation by one side (routine stress testing following revascularization is one such example). But there are no cases where a class I vs a class IIb or III discrepancy exists. What is clearly evident, however, about the tables within the article by James et al are the 
large section where there are guidelines which present select details on one side of the Atlantic, but go unaddressed on the other side. Surely, panel members can have strong biases for certain subpopulations but, overall, these do not appear to be randomly distributed. Perhaps, where freedom in action is desired, no response is safer than words that enslave us to prescribed pathways.

\section{WHAT IS LEFT UNSAID}

The US and European health systems are difficult to compare because of the variability in the degree of socialization between European countries. The US, however, is still largely a fee for service enterprise (though it is changing). Certainly it was in 2011 when the majority of the guidelines were under development on ischemic heart disease. The highest fees for physicians and hospitals are generated in the catheterization labs. While there is certainly noise in the classification of appropriateness, in general this is a force in practice. The other strong influence is the emergence of the hospital as the dominant player in US health care. Since hospitals now control the majority of physician practices, they wield significant influence on physician behavior. One such influence is the financial advantage of short hospital stays. Consequently, tests that produce value but take time and do not produce definitive therapy are at a disadvantage to those that do. This subtle thread runs through the US guidelines presented.

\section{Shortening Hospital Stays}

A number of the US guidelines can be interpreted as indirectly shortening inpatient days. All the noninvasive guidelines following an acute event are classified as IIB indications whereas the European approach is to offer no guidance (see Table 3). These center around ischemia/ viability-directed intervention. Generally, such testing would occur the following day once the coronary anatomy was known and the initial intervention performed. Since it is a class III indication to perform PCI in the acute setting of a non-culprit vessel, the prevalence of patients with significant residual vessel disease is high. Staging the procedure using noninvasive functional imaging as a decision tool would seem to be a wise approach, rather than relying on visual assessment of the coronaries and guesses about viability. However, this potentially adds to the length of stay, which is a metric for hospitals. Consequently, there are few class I or IIa guidelines for noninvasive imaging in known $\mathrm{CAD}$ in the inpatient setting.

\section{Slant Toward Invasive Coronary Angiography}

In general, there is a slight bias to perform angiography invasively for many intermediate and high risk patients, although this is not consistent throughout all the tables. Table 1 shows angiography in a prominent role for suspected ischemic heart disease in higher risk patients. What is not prominent is the noninvasive use of coronary CTA as a substitute for coronary angiography. There are no approved indications for CTA in any of the US guidelines with the exception of intermediate risk patients who cannot exercise. CT cardiac imaging has undergone a remarkable improvement in technology and a significant reduction in radiation with newer equipment and techniques. CTA has been shown to compare favorably with all other forms of noninvasive testing that are recommended in these guidelines. ${ }^{8}$ This includes patients with bypass grafts and stents $>3.0 \mathrm{~mm} .{ }^{9,10}$ The advent of new techniques is likely to reach smaller stents. ${ }^{11}$ It remains a puzzle as to why CTA is singled out by the US. It does have the potential to reduce diagnostic invasive angiography volume 12 which would generate economic concerns for clinical practices and it does shunt that work for many centers, out of cardiology and into radiology departments. The European guidelines avoid CTA in their recommendations.

\section{Percutaneous Revascularization}

The US guidelines tend to give a freer hand to cardiologists when PCI is an issue. In the eight PCIfocused guidelines in this review, only two are addressed by the US panel. In fact, of the 12 unaddressed guidelines by the $\mathrm{US}^{1}{ }^{1}$ half relate to PCI. Conversely, six are addressed by the European panel with a small predominance of negative classifications. This may reflect a hesitancy in the US to constrain PCI use. The coronary catheterization lab is a large component of most cardiology practices. At this time, it has significant economic impact.

\section{Uncertain Future}

The guidelines presented here were developed before many of initiatives of the Affordable Care Act were in place. Marked changes in how providers are paid are in development. These include bundled payments for specific diagnoses that are value based. The guidelines have been the foundation of many of these changes. Practices that are cost effective, of known benefit, and of high quality will be economically incentivized. This current approach should produce a 
broader, more comprehensive set of guidelines in cardiology as the incentive to perform specific highcost tests will be curtailed. In fact, they will be counted against the provider where they are used outside the guideline boundaries. Consequently, these guidelines are an important component of the healthcare system. Should this path be diverted, as seems likely, then much of the economic pressure to perform high paying procedures will return and guidelines will remain unsaid to preserve flexibility. It will be up to the US healthcare system to continue do the right thing.

\section{Disclosure}

The author has no disclosures.

\section{References}

1. Stirrup J, Velasco A, Fadi H. Guidelines in review: Comparison of ESC and ACC/AHA guidelines for myocardial revascularization. J Nucl Cardiol. 2017. doi:10.1007/s12350-017-0811-5.

2. Fihn SD, Gardin JM, Abrams J, Berra K, Blankenship JC, Dallas AP, et al. 2012 ACCF/AHA/ACP/AATS/PCNA/SCAI/STS Guideline for the diagnosis and management of patients with stable ischemic heart disease. J Am Coll Cardiol. 2012;60:e44-164.

3. Diamond GA, Forrester JS. Analysis of probability as an aid in the clinical diagnosis of coronary-artery disease. NEJM. 1979;300: $1350-8$.
4. Diamond GA, Forrester JS, Hirsch M, Staniloff HM, Vas R, Berman DS, et al. Application of conditional probability analysis to the clinical diagnosis of coronary artery disease. J Clin Invest. 1980;65:1210-21.

5. Diamond GA. Monkey business. Am J Cardiol. 1986;57:471-5.

6. Fihn SD, Gardin JM, Abrams J, Berra K, Blanhenship JC, Dallas AP, et al. ACCF/AHA/ACP/AATS/PCNA/SCAI/STS Guideline for the diagnosis and managementof patients withstable ischemic heart disease. J Am Coll Cardiol. 2012;60:e44-164.

7. Boden WE, O'Rourke RA, Teo KK, Hartigan PM, Maron DJ, Kostuk WJ, et al. Optimal medical therapy with or without PCI for stable coronary disease. N Engl J Med. 2007;356:1503-16.

8. Douglas PS, Hoffmann U, Patel MR, Mark DB, Al-Khalidi HR, Cavanaugh B, et al. Outcomes of anatomical versus functional testing for coronary artery disease. N Engl J Med. 2015;372:1291300.

9. Weustink AC, Nieman K, Pugliese F, Mollet NR, Meijboom WB, van Mieghem C, et al. Diagnostic accuracy of computed tomography angiography in patients after bypass grafting: comparison with invasive coronary angiography. JACC Cardiovasc Imaging. 2009;2:816-24

10. Sheth T, Dodd JD, Hoffmann U, Abbara S, Finn A, Gold HK, et al. Coronary stent assessability by 64 slice multi-detector computed tomography. Catheter Cardiovasc Interv. 2007;69:933-8.

11. Wang LF, Tao LW, Huang MX, Liao WB, Zhu YZ, Zhou WB, et al. Clinical evaluation of coronary in-stent restenosis using dualsource computed tomography. Echocardiography. 2015;32:16817.

12. Schoepf UJ, Suranyi P, Thilo C, Costello P, Zwerner PL. Replacing diagnostic catheterization with coronary CT angiography: the final frontier. Eur Heart J. 2007;28:2305-6. 